\title{
A Visual Analysis of a Malaysian English School Textbook: Gender Matters
}

\author{
Mohamad Subakir Mohd Yasin ${ }^{1}$, Bahiyah Abdul Hamid ${ }^{1}$, Zarina Othman², Kesumawati Abu Bakar ${ }^{1}$, \\ Fuzirah Hashim ${ }^{1} \&$ Azmah Mohti ${ }^{3}$ \\ ${ }^{1}$ School of Language Studies \& Linguistics, Faculty of Social Science and Humanities, Universiti Kebangsaan \\ Malaysia, Bangi, Malaysia \\ ${ }^{2}$ Centre for General Studies, Universiti Kebangsaan Malaysia, Bangi, Malaysia \\ ${ }^{3}$ Faculty of Science and Technology, Universiti Kebangsaan Malaysia, Bangi, Malaysia \\ Correspondence: Zarina Othman, Centre for General Studies, Universiti Kebangsaan Malaysia, 43600 Bangi, \\ Malaysia. Tel: 60-3-8921-6917. E-mail: zothm@yahoo.co.uk
}

Received: July 9, 2012 Accepted: August 9, 2012 Online Published: September 20, 2012

doi:10.5539/ass.v8n12p154 URL: http://dx.doi.org/10.5539/ass.v8n12p154

\begin{abstract}
In the Malaysian education system, attention is highly paid on reading words. Visual images are often treated as "decoration", or are dismissed altogether (Kress \& Leeuwen, 1996). Many local researchers (Saedah 1990, Bahiyah et al., 2008) have only analysed written texts to see how social practices deemed negative such as gender biasness are reflected in the words (lexical items) and linguistic structures. Currently, no systematic research has been undertaken in Malaysia to analyse visual images in English language school textbooks to study how visual images can reflect gender biasness. This research project addresses gender biasness found in visual images in school textbooks, i.e., the treatment of one gender over the other especially of women and girls. The project adopts three widely used approaches for analyzing visual images; content, socio semiotic and ethno-methodology analyses. This paper will however highlight its preliminary analysis focusing on image analysis based on participation, gender and representational meanings. Its aim is to identify the types of images and the representation of gender biasness and stereotyping found in the textbook. The preliminary findings should expose the sexism and gender biasness in the visual images of a sampled textbook; i.e. an English school textbook that is abound with visual images that sometimes, more so than written texts, can articulate more forcefully social and cultural meanings.
\end{abstract}

Keywords: second language teaching, school textbooks, visual analysis, socio semiotic, gender stereotyping

\section{Introduction}

Research into the area of sexism in the English language and its impact on society can be traced back to the early 1900s. Since then, studies on language and gender have been carried out extensively. Within the larger spectrum of studies on gender biasness and practices of stereotyping, school's textbooks have drawn particular interest among numerous researchers over the past decades (Mohamad Subakir et al., 2012; Mohd Faiez Ikram et al., 2011; Habibah et al., 2012; Bahiyah et al., 2009, 2008). Gender is one of "a microcosm of ideologies, values, and beliefs" (Taylor, 2003). Therefore, messages about gender roles and gender identity that are transmitted through these texts are thought to affect the future behaviour of the children who consume them as they formulate their own roles in society (Eisenberg, 2002) This is a point which is further stressed by Knowles and Malmkjaer (1996) who contend that children have the ability to both "promote certain beliefs and certain forms of behaviour while discouraging others".

Research on gender construction in school textbooks can serve children well. A heightened sense of awareness about gender disparities could lead to conscious steps being taken by writers, illustrators and publishers to provide children with access to children's books that avoid sexist practices. Clark (2002), for example, observes that in recent decades, the extensively analysed 'Caldecott Award' winning books in the United States "have been much more likely to feature female characters" and in less stereotyped ways compared to children's books from the 1960s. Therefore, in more recent publications, children, both girls and boys, have the opportunity to see 
themselves in a greater range of roles, activities and settings. This is a significant step in reducing the social stereotyping of gender identity.

Another reason why gender construction in schools textbooks has continued to hold the attention of researchers is the fact that gender awareness and instruction have featured prominently in the school curriculum, and thus the need to explore gender biasness. In Malaysia, English language has been revitalised in the classrooms as the language continues to be regarded as crucial for the country's growth. The teaching of English has obviously been the focus of attention because the supply of a Malaysian workforce competent in the English language is very much dependent on the emphasis placed on the language within the primary and secondary school curricula.

A major area in the study of gender and gender construction that is still lacking is the visual analysis even though there has been several studies in recent years that focus on images/visuals identity such as the one conducted by Kesumawati (2012). Zarina et al. (2012) analyse the frequency count of visual images in a selection of Malaysian English school textbooks for instance. Although their study is helpful towards the general understanding of the importance of visual analyses when analyzing texts (instead of just focusing on the written representation), there is still much to be done and to be understood especially as to what roles images/visuals have in shaping gender awareness among Malaysian pupils. This study hence attempts to address some of the preliminary concerns of image analysis in relation to gender stereotyping in Malaysia. This paper discusses the preliminary analysis of the study and addresses these research questions:

1) What types of visual images are found in the selected English primary textbooks used in Malaysian schools?

2) To what extent are gender biasness and stereotyping represented in the visual images of the selected Malaysian primary English school textbook?

\section{Methodology}

One Malaysian English Primary One textbook published in 2004 was selected for analysis. The unit of analysis consisted of images in the books and the inclusion of each image was determined by two main criteria: (1) the presence of participants (these maybe people, animals or inanimate objects) and (2) clear culturally defined gender of either male or female. Images displaying narrative containing more than 20 participants, participants with unspecified gender and displaying only circumstance of location are excluded from our analysis. Selected images are confined to illustrations, which in this study is defined as graphic or commercial art that is created for client to fulfil a task (in this case, the task of educating the readers) (Zeegen, 2009) and does not include visual such as photograph, chart, tables and diagrams. Based on these criteria the total of images selected for visual analysis is 78 . A combination of content analysis and social semiotic approach is used to examine the representations of gender in the images. This combination involves quantifying visual representation using explicitly defined categories based on Kress and van Leeuwen (2006) grammar of visual design. Images will be annotated and coded using UAM Corpus tools for different elements (e.g. participants, vectors, circumstances etc.) (Figure1).

Based on the purpose of this paper, focus will be specifically given to the dimensions of the ideational meta-functions ( Halliday, 1994; Kress \& van Leeuwen, 2006). As our visual analysis deals with representational meaning, the following paragraphs describe the resources for codifying participants, action and circumstances in images. Ideational meta-function focuses on represented patterns of real world experience in the images. This involves looking at the participants in the images (who), the actions (what is happening) and the circumstances (where) surrounding the participants. Based on the research questions, it is hypothesised that a) there are significantly more male than female participants in the images and b) Female participants are often depicted in the private sphere (indoor, home) while male participants in the public sphere (outdoor, institutional building). Accordingly, male participants are represented as occupying more institutional roles than female participants whilst female participants are represented as assuming more domestic roles than male participants.

In examining the depiction of participants or characters (Kress \& van Leeuwen, 2006) in the textbook images, in our initial analysis, the participants can be a representation of human or non-human entities. These two contrasting options must display clear identifiable gender of either male or female. Gender in this study is defined as a form of cultural categorisation and is signified by means of standard attributes such as dress, hairdo, facial features and so on (van Leeuwen, 2008). Gender is a form of social identity; hence, cultural categorisation in van Leeuwen's network (2008) is extended to include the feature of social, with gender being one of its subcategories. However, based on what we observe in our data, cultural categorization of participants is normally a simultaneous representations of gender (male or female), institutional identity (e.g. school uniform), ethnic identity or relational identity (e.g. casual home/play clothes). 


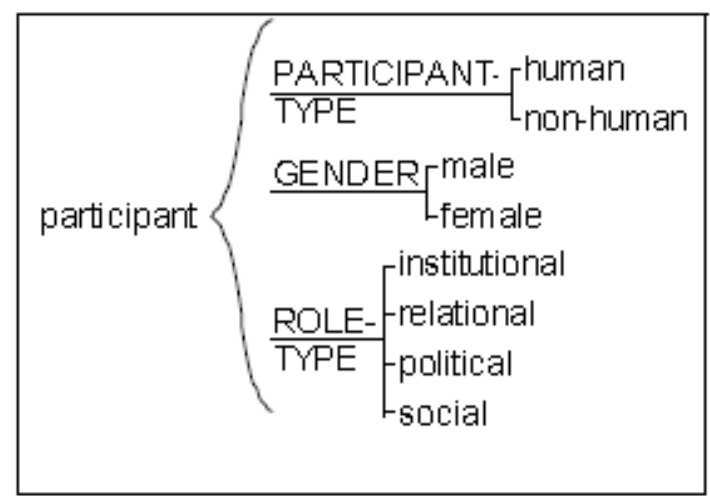

Figure 1. A Summary of participant image analysis

In coding the actions and circumstances, we adapted the term proposed by Painter \& Martin (2010) based on Kress and van Leeuwen's narrative system (2006) by extending the level of delicacy. Narrative is labelled action (i.e. realised by vectors originating from one participant and directed at another participant) or reaction (whereby a participant is on the receiving end of a vector, e.g. being looked at by another participant). We extended the level of delicacy by adding four contrasting types of action based on what is represented in our data; these types are 1) social (such as playing with a ball or flying a kite), 2) institutional (e.g. reading or writing), 3) political (e.g. giving a speech) and 4) personal (e.g. washing dishes, eating or cooking). Circumstance of setting refers to the location of the participants and is extended to include the features of indoor and outdoor. Circumstance of means refer to an object that provides the means for carrying out the action such as a ball or a bicycle.

The data are annotated using UAM Image Tools program. Each of the system and its features form the basis for the systematic annotation of participants, actions, circumstances and feelings in the images. Participants, actions and circumstances are normally realized in different forms within a frame; this program allows for the annotation of parts of different sizes (or as a whole) according to different ideational and interpersonal meanings. Features of the systems are used as the coding schemes for visual classification. Parts of images are then highlighted and features from the system are assigned to the highlighted part (Figure 2). Frequency occurrences of features can be derived from the completed annotation. Additionally, we can also search for instances of specific features in the annotated corpus (e.g. female and institutional or male and relational).

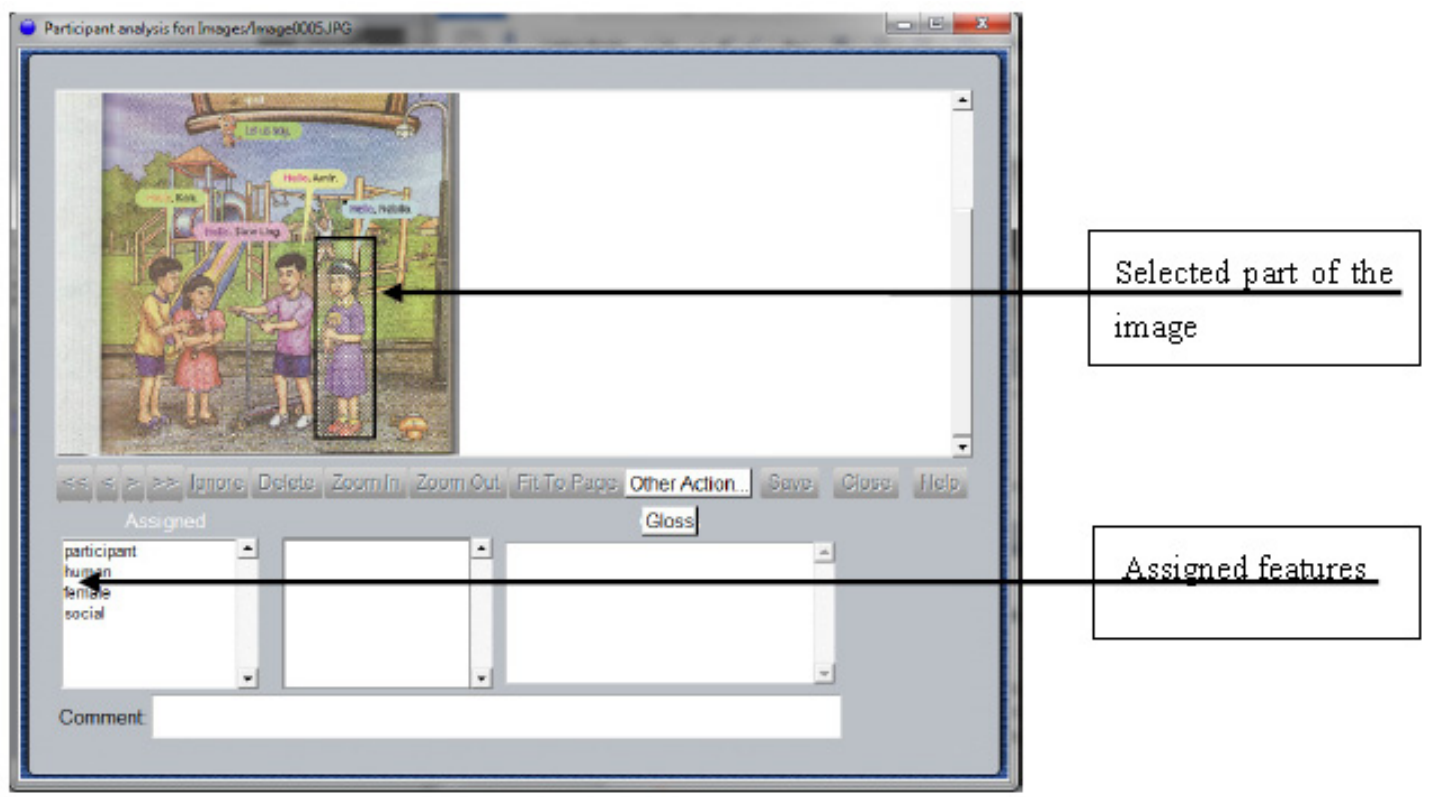

Figure 2. Annotated image with its assigned features 


\section{Findings and Discussion}

The analysis of images for this paper focuses on the participant, gender and representational depictions for the primary school textbook analysed, Kurikulum Bersepadu Sekolah Rendah: English Year 1, published in 2004 by Dewan Bahasa and Pustaka (The Institute of Language and Literature). The discussion of the preliminary findings of this study will begin with the depictions of participant through participant type and gender type analysis followed by the representational meaning analysis.

\subsection{Depiction of Participant}

The depiction of participants/characters can be analysed via 1) participant type and 2) gender. Participant type may be human or non-human. Within the non-human type, there is a distinction of whether the depiction of participants or characters is animals or objects.

\subsubsection{Participant Type}

In general, the analysis reveals a total of 337 participants/characters of both human and non-human categories. There are 297 human participants $(88.13 \%)$ as opposed to 40 non-human participants $(11.87 \%)$ which illustrate that human participants/characters play a big role in the textbook. With regards to the non-human category, the analysis reveals participant/character depictions where they are either animal, specifically bears, rabbits, cats, ants, chickens, bees, ducks, moles and mice or object, for instance, a pen.

\subsubsection{Participant and Gender Type}

The analysis for gender of participants or characters depicted in the textbook reveals that overall (human and non-human) 195 participants were male while 142 participants were female. With regards to the distinction between human vs. non-human, the analysis shows that the human participants/characters depicted in the textbook totalled 172 human males $(88.21 \%)$ as opposed to 125 human females $(88.03 \%)$. In contrast, the non-human participants/characters depicted in the textbook totalled to 23 non-human males $(11.79 \%)$ and 17 non-human female (11.97\%). As discussed above, this textbook relies heavily on human participants/characters more than non-human participants' characters. This is rightly so because the text under scrutiny is a textbook rather than a reader or a storybook. Furthermore, the males, whether human or non-human are more visible in this textbook.

Non-human animal and object depictions are accorded gender from cues in the text that accompany the images. These cues may act alone or are used in combination. These cues may be in the form of masculine and feminine proper nouns in naming conventions such as male rabbits being named Bob and Rob, a male bear bearing the name Ben and a male object, specifically a pen named Ben - "Ben the pen". In this book, non-human females are all animals $(100 \%)$, there are no objects that are depicted as female. Non-human females found in this textbook besides bears are cats-"Cutie cat"; a mole and a mouse - "Molly mole's mother met Mary mouse". The use of pronoun can also be a cue to whether the referent is a male or female, for example an ant through the use of the proper noun (Andy ant) is male and the masculine pronoun "he" follows in tandem -" Andy ant...he is in the can". In the case of female non-humans we see the same pattern: "Where is Cutie cat?.She is on the mat". Further, conventional clothing for males and females also act as cues to the participant's gender where male bears are depicted in trousers and t-shirts and female bears are depicted wearing a dress. Elsewhere, a chicken is depicted in dress with frilly sleeves and an apron. What is typically feminine is the ribbon that the female bear wears on her head that differentiates her visually as distinctively female

\subsection{Representational Meaning}

Representational can be defined as: 1) fine arts depicting or attempting to depict objects, scenes, figures, etc directly as seen; naturalistic and 2) of or relating to representation. This section reports on the representational meanings of actions, i.e., as to what participants are doing as well as where are the actions illustrated taking place in the images. This representational analysis of the images should indicate gender biasness and focuses on three main domains of action followed by the character and setting analysis.

\subsubsection{Action}

The images analyses actions that illustrate gender stereotyping that are found in the social, institutional, relational and political as well as no-action categories. The highest percentage of distribution is of the institutional with $37.69 \%$ (127/337 in number) followed closely by the social action type at 32.64\% (110/337). The institutional category seems to portray the most male and female depictions followed by the social and relational categories. There are however interestingly, no depictions of participants found in political category. 


\section{a) Social}

The analysis in general, shows that there are more social actions that relate to male than females for both human (64 male/56 female) and non-human. From the social perspective, the most observable action illustrated is the 'playing' action with the highest percentage of $28.18 \%$ of all actions depicted. In such instances, the illustrated images show a more masculine than feminine type of 'playing'. For instance, for both human and non-human, masculine 'playing' is illustrated by boys playing 'football' and girls playing 'skipping'. This is an indication of gender stereotyping where typically football is associated with boys playing football whereas skipping is associated with girls playing skipping. In other words, playing with a 'ball' is often associated with boys. However, it is found that there is an occurrence of non- stereotyped image of actions illustrated from the social perspective. For instance, there is an image of a boy playing on a swing and girls and boys together playing with a 'ball' though it is not a football/ soccer kind of playing. It is also found that as for social action type, the other common image depicts the 'holding' action (11.82\%) after talking (14.55\%). This holding action refers to items held by characters which indicate an element of gender stereotyping. For instance, for such holding actions, females are illustrated to be holding for instance flowers $(15.38 \%)$, soft toys $(30.77 \%)$, fruits and presents $(15.38 \%)$ whereas males $(15.38 \%$ human and non-human) are illustrated to be holding on to a bicycle or $(7.69 \%)$ holding a ball. These are apparent evidence of stereotyping of objects that are associated with boys and girls.

b) Institutional

From the institutional perspective, images are illustrated most commonly in school classrooms or school playgrounds. Thus, actions depicted are mostly 'learning' actions. For instance images commonly depict male and female students sitting down at their desks, answering questions, reading or writing in the classroom (Figure 3).

Based on the frequency number between boys and girls, the image evidently illustrates more boys than girls. It is evident that there are more boys (6) than girls (4) in the image shown above. A ratio of an average of 1 girl to 2 boys indicates a certain level of gender biasness in the image as a whole. It is worth to note that those depicting the role of asking questions are the boys and they are prominently the ones sitting at both heads of tables; i.e., acting as the leader of each group. The image does illustrate 3 girls raising their hands up to volunteer to answer questions indicating girls being perhaps the more enthusiastic ones in gesturing to answer but never getting the chance to answer. The image depicts the boys to be the ones to answer questions and to provide the correct answers, i.e., "yes it is' and 'no, it is number 8'; the girls are voiceless. Another gender stereotyped action found is the image of girls in the act of 'serving' food to the boys (Figure 4). This act by nature illustrates the gentle action often associated with girls to show femininity. It further illustrates the nurturing aspect of female characters often depicted or described.

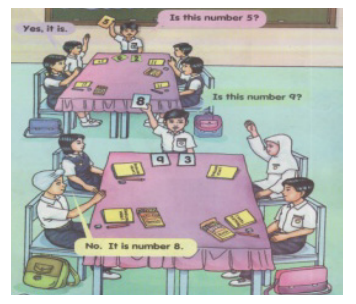

Figure 3. Males and females in the classroom

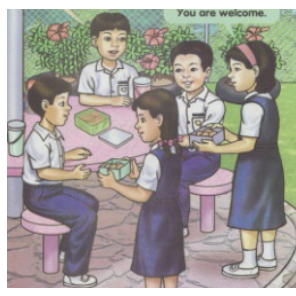

Figure 4. Girls serving food to boys

\section{c) Relational}

Actions that are categorised as relational are often illustrated within family members; i.e., mother / daughter or father/ sons or parents / children. The action depicted in the image (Figure 5) depicts an image of mother and daughter in the kitchen. It depicts a 'cleaning' action in a kitchen setting with only 2 female characters (mother and daughter) with no male characters of father and son in the kitchen. It displays an apparent gender stereotyped act of 'women' being the ones to accomplish tasks in the kitchen like washing the dishes and drying them. It is worth noting that both the participants are illustrated wearing aprons which indicate the stereotyping of women to be more suited to wearing aprons than men. 


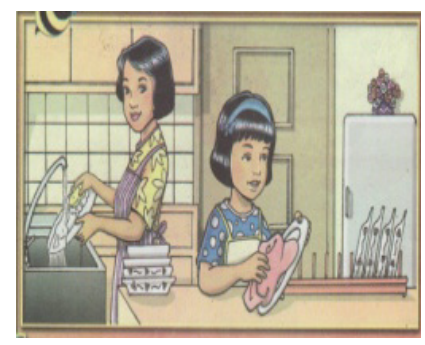

Figure 5

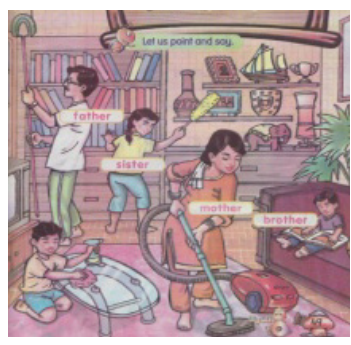

Figure 6

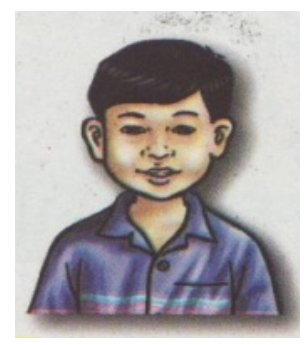

Figure 7

The image in Figure 6 illustrates a relational concept of a family cleaning their living room. Both male and female participants are depicted cleaning the living room. The action of cleaning is clearly depicted along gender lines, i.e., the father is cleaning the ceiling while the mother is seen hovering. It depicts the more difficult task; hence the more masculine task to be dealt by the father and the less difficult chore whilst the feminine task is dealt by the mother. The image also depicts the daughter dusting using the duster whilst the son is depicted wiping the table with a cloth. This relates to our earlier discussion regarding the connotation of 'items' or 'objects' to specific gender. The analysis also identifies a 'no action' category which refers to the illustrations of images where the participants do not perform any actions. Their images are in the form of still pictures or portraits (Figure 7). The males and females in this category are found to be about equally represented for both human and non-human participants. As for political aspect, no images on political actions are represented in this textbook.

\subsubsection{Character}

The second domain of representational analysis is character that is further discussed under the sub-topic of character type and ethnicity. The images depict actions that illustrate gender stereotyping analysed from the social, political, institutional, relational as well as no-character categories.

\section{I) Character type}

\section{a) Social}

For this category, the general analysis shows that there are more social character that relate to male than female for both human (35 male vs. 31 female in number) and non-human. Most of the social types featured are as a 'friend' whereby there are 75 (96.15\%) occurrences altogether. For this, male characters are more dominant than female characters (43 compared to 32 participants, respectively). Female characters are also featured as a 'neighbour' (2.94\%) and a 'school canteen food seller ' $(2.94 \%)$ whereas a male character $(2.27 \%)$ is featured as a 'driver'. This is an indication of gender discrimination as a person can become a 'friend' to any gender, whether male or female. Besides human, animals and objects are also depicted in a social circle of friends. In Figure 8 for instance, there are two kinds of animals, the mole and the mouse that look like good friends as both are smiling and talking to each other (Molly mole's mother met Mary mouse).

b) Institutional

More male characters are depicted as teachers in the institutional setting compared to females ( 8 males and 5 females). As for non-human teachers, only males are depicted (Figure 9). A similar pattern can be seen whereby more male characters for both human and non-human are depicted as students ( 65 males and 39 females). In this institutional setting, a large proportion of participants are depicted by male characters. This can be seen in the image below that depicts more male dominance. Besides the teacher, who is a male, 4 out of the total of 6 students are also males. This image is clearly an example of gender stereotyping as for both human and non-human, the institutional setting tends to imply that there is male dominance in education.

\section{c) Relational}

Characters of this category are shown within family members namely mother, father, son, daughter, sister and brother. Overall, mothers are depicted as more significant than fathers ( 24 mothers and 17 fathers). There are mothers for non-human characters as well but no father figure is depicted. Sons are more depicted than daughters in humans; in fact no daughter is found at all in non-human. There is only one non-human character depicted as a son. Despite this, sisters are depicted more than brothers in humans but none of the siblings are found in non-humans. The image in Figure 10 portrays the mother playing a substantial role in attending to her children's needs. In this image, the mother is helping her son to choose a shirt for him and the daughter is probably eager 
waiting for her turn to be attended to as well. This image exhibits the traditional role of a mother in this culture to provide the loving care and support needed by growing children.

In this textbook, there are no images related to political aspect. There are however, 'no character' images which refer to parts that are not illustrated in the context; for example, only the portraits of the participants are shown, the pictures are 'still' pictures and the images are single images.

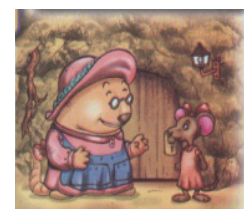

Figure 8. Social

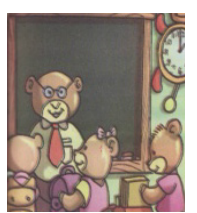

Figure 9. Institutional

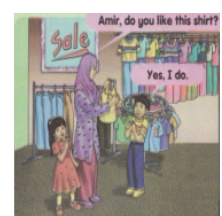

Figure 10. Relational

\section{II) Ethnicity}

In the analysis of images, ethnicity in the Malaysian context may be revealed through cues that may be in the form of cultural attributes such as objects, dress, hairstyle, headwear (Van Leeuwen \& Jewitt, 2001) markings on the face of religious significance, facial and physical features as well as skin colour. Also of great importance in the analysis, are naming conventions found in the text that accompany the images which can clearly denote whether the participant/character belongs to a particular ethnic group.

In the images below, the participant in Figure $11 \mathrm{can}$ be identified as a Malay girl. Islam is the official religion of Malaysia and is practiced by more than $60 \%$ of the ethnic Malay population. The female participant in the image is depicted wearing headwear that measures to the Muslim standards of modesty. In Figure 12, we can identify the boy as belonging to the Sikh ethnic group also through the headwear. The sikh boy is depicted as wearing a 'patka'; a piece of cloth over a knot of hair (equivalent to a turban for adult Sikh males). In Sikhism, the headwear donned by males such as the 'patka' and the turban is donned not for cultural significance but they are donned more so for spiritual significance; out of obedience of the wishes of the founders of the faith. In the next 2 figures, we see a darker skinned girl (Figure 13) and a lighter skinned girl (Figure 14) and their ethnicity is brought to bear from the identification of the proper nouns; their names; Sunita (Indian) and Siew Ling (Chinese). These names are common female names related to their ethnic groups. Also reliable in identifying ethnicity in the case of the two images are the facial features and markings on the face of religious significance (Figure 13, the black 'pottu' on the forehead, i.e., a small round black mark that signifies that the girl is unmarried).

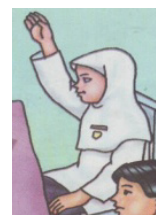

Figure 11. Malay girl

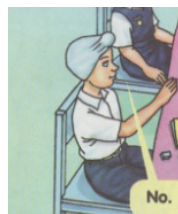

Figure 12. Sikh boy

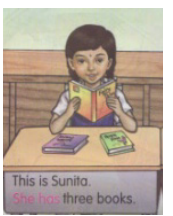

Figure 13. Indian girl

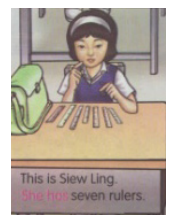

Figure 14. Chinese girl

The analysis of images related to ethnicity yielded two categories: the clearly identifiable participants/characters belonging to ethnic groups and those that are unidentifiable. In the clearly identifiable category, the analysis revealed the following: In general, the images found represented the three largest ethnic groups namely Malays, Chinese and Indians with also the Sikh ethnic group also represented. In this textbook there is a large preponderance on human Malay males and females (41 and 39 respectively). For the Chinese and Indian ethnic groups, there are more human Chinese (12 as opposed to 8) and Indian (15 as opposed to 11) females than males represented in the textbook. Interestingly, no non-humans were found to be representing any of the ethnic groups discussed.

The analysis of images related to ethnicity yielded two categories: the clearly identifiable participants/characters belonging to ethnic groups and those that are unidentifiable. In the clearly identifiable category, the analysis revealed the following: In general, the images found represented the three largest ethnic groups namely Malays, Chinese and Indians with also the Sikh ethnic group also represented. In this textbook there is a large preponderance on human Malay males and females (41 and 39 in number respectively). For the Chinese and Indian ethnic groups, there are more human Chinese (12 as opposed to 8$)$ and Indian (15 as opposed to 11) females than males represented in the textbook. Interestingly, no non-humans were found to be representing any of the ethnic groups discussed. 


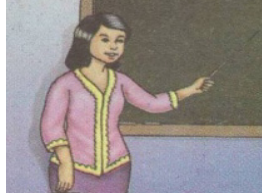

Figure 15. Baju Kebaya

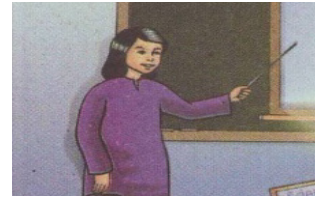

Figure 16. Baju Kurung

The females in Figures 15 and 16 are seen wearing the traditional Malay dress of baju kebaya and baju kurung. The Malay word "baju" may mean "dress" or "clothing" depending on the context of use. In recent years, the Malaysian goverment's policy for ethnic integration has allowed for female non-Malays also doing the baju kebaya and baju kurung especially for formal and official functions and this trend is also seen with other ethnic traditional clothings/dress being worn by all ethnic groups. For instance, the cheongsam, the traditional wear of Chinese females or the salwar kameez, the traditional wear of Sikh females which is a long tunic worn over trousers and with a matching shawl is very popular now with Muslim women as it conforms to the ideals of modesty and women of all ethnicities are also seen to be wearing it for fashion as well as comfort. Very soon we will not be able to confidently identify ethnic identity with dress. Western style skirts, blouses, dresses, trousers, t-shirts and shoes are also popular for every day wear especially for female children of all ethnicities.

\subsubsection{The Setting}

Another feature analysed in the data is the 'setting'. This refers to the setting or context in which participants are most commonly depicted. The findings highlight 2 types of setting mainly; the indoor setting and the outdoor setting. Overall, more outdoor activities are featured. As for outdoor setting, $45.99 \%$ of participants are depicted outdoors with $38.58 \%$ in indoor setting and no setting at $15.43 \%$. This no-setting refers to characters depicted in a setting of no background such as a photo portrait image.

A $38.58 \%$ of characters (44) out of the 130 characters found in indoor setting are portrayed for both human and non human participants. The frequency shows more male than female as a whole for humans (67 / 52). The non humans are portrayed equally as per gender. The classroom setting makes up the most of the setting for the indoor activities. Home setting in the second most frequent setting depicted

The park setting makes the most of the setting for the outdoor activities with the dominance of $34.19 \%$ compared to others as shown below. As for human participants, male participants are the most dominant (81 to 53) participants depicted. More male non-humans are also portrayed in the outdoor setting than the female (15 to 6). The images in Figure 17 and 18 depict the balance or imbalance of the number of male and female participants. On the whole, the frequency of male participants dominates female participants in most of the outdoor settings and the specific settings identified were in the park (33 to 20), in schools (12 to 3 ) and in playground (10 to 5).

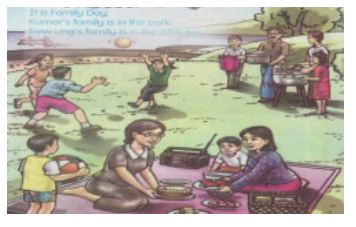

Figure 17. Outdoor: human

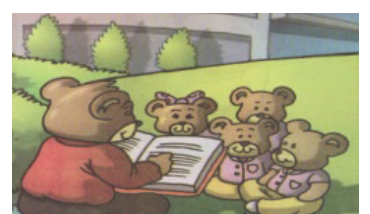

Figure 18. Outdoor: non human

\section{Conclusion}

In this paper, we seek to contribute to the emerging literature specifically, those that highlight issues related to gender, inclusiveness and equity in school textbooks. The image analysis carried out on the textbook reveals a clear gender imbalance in favour of males mostly. The analysis reveals that the domain relegated to female participants is still the private sphere while male participants are predominately represented in the public sphere usually outdoors. In the textbook analysed, stereotypical gender roles of wives, mothers and nurturers are allotted to women and they are largely confined to the private world of the home, represented by equally private spaces such as the garden and the back yard (see amongst others Zarina et al., 2012, Bahiyah et al., 2008). In the real world, Malaysian women are entering the workforce in increasing numbers, many taking up unconventional professions and to portray them in the private sphere of the home and in nurturing roles is inaccurate. Giving equal prominence to males and females in the representation of professional and diverse occupations in images as well as in the text may help encourage females to consider a full range of career options and possibilities in different spheres of society. With regards to actions or activities, females are more often relegated to a limited array of indoor activities. They are depicted to be responsible for domestic chores specifically in the kitchen, around the garden and in the 
backyard. Males are depicted in a wider range of activities, some indoors but especially those that involve outdoor settings namely in the playground, in the park, at the beach and at playing fields and they partake in active sports such as cycling, playing football, basketball and so on. Textbooks via gender equitable images can be a potential source of content and a viable tool for introducing and reinforcing a physically active lifestyle for both males and females (Nigles \& Spencer, 2002). This will spearhead more women to participate in sporting events and make a name for themselves as according to Bahiyah et al., (2008), "The stereotypical perception of women in sports is that they are not up to par with their male counterpart".

A number of images of girls especially in the school environment specifically those in the classroom depict girls in marginal roles in contrast to boys who are depicted as assertive, intellectual, apt at decision-making and taking leadership roles (see among others Zarina et al., 2012;Bahiyah et al., 2008). Further, there is an absence of positive female role models for girls to identify with. A gender perspective must be integrated into teacher education and training programs so that educationists may play a crucial role in addressing the issues of gender, inclusiveness and equality, providing valuable input for the formation of gender equitable curriculum, pedagogy and policies. Materials developers, textbook writers, editors, illustrators and those directly involved in producing educational textbook, resources and materials may also benefit greatly from a gender perspective. Input by parents is equally important especially those that bring gender concerns to the fore in the process of nurturing the mindsets of their children. It would be a healthy endeavour if we could study how girls and boys react to visual representations that perpetuate sexism and gender stereotyping and to study how they can challenge prevailing stereotypes that undermined equality. The suggestions highlighted above provide us with impetus to further our investigations.

\section{Acknowledgements}

This paper is based on a study funded by the Research University Grant (GUP), Universiti Kebangsaan Malaysia. Research Code: UKM-GUP-2011-148

\section{References}

Bahiyah Abdul Hamid, Mohamad Subakir Mohd Yasin, Yuen Chee Keong, Zarina Othman, Azhar Jaludin, \& Kesumawati. A. Bakar (2009). Linguistic Sexism and Gender role stereotyping in Malaysian KBSR n KBSM English Language Textbooks: implications to nation building. Final report: study funded by the fundamental research grant scheme UKM-SK-04-FRGS0001-2006. Ministry of Higher Education Malaysia.

Bahiyah Dato' Hj. Abdul Hamid, Mohamad Subakir Mohd Yasin, Kesumawati A. Bakar, Yuen Chee Keong, \& Azhar Jaludin. (2008). Linguistic Sexism and Gender Role Stereotyping in Malaysian English Language Textbooks. GEMA Online Journal of Language Studies, 8, 45-78.

Clark, R. (2002). Why All the Counting? Feminist Social Science Research on Children's Literature. Children's Literature in Education, 33(4), 285-295. http://dx.doi.org/10.1023/A:1021276729780

Eisenberg, K. N. (2002). Gender and Ethnicity Stereotypes in Children's Books. Dissertation Abstracts International: The Sciences and Engineering, 63, 1-8.

Habibah Ismail, Bahiyah Dato Hj Abd Hamid, Mohamad Subakir Mohd Yasin, Zarina Othman, Yuen Chee Keong, \& Azhar Jaluddin. (2012). A Study of Gender Positioning and Occupational Roles in Selected Primary School English Language Textbooks. The International Journal of Learning, 18.

Halliday, M. A. K. (1994). An Introduction to Functional Grammar (2nd ed.). London: Edward Arnold.

Kesumawati A. Bakar. (2012). Gendered Identities in Online Personal Advertisements: A Malaysian Perspective. Unpublished $\mathrm{PhD}$. Thesis, University of Sydney, Australia.

Knowles, M., \& Kirsten, M. (1996). Language and Control in Children's Literature. London/New York: Routledge.

Kress, G., \& Van Leeuwen, T. (1996). Reading Images: The Grammar of Visual Design. London: Routledge.

Kress, G., \& van Leeuwen, T. (2006). Reading images: The grammar of visual Design (2nd ed.). London: Routledge.

Mohamad Subakir Mohd Yasin, Bahiyah Abd Hamid, Yuen Chee Keong, Zarina Othman, \& Azhar Jaludin. (2012) Linguistic Sexism in Qatari Primary Mathematics Textbooks. GEMA Online Journal of Language Studies. 12(1). 
Mohd Faeiz Ikram bin Mohd Jasmani, Mohamad Subakir Mohd Yasin, Bahiyah Abd Hamid, Yuen Chee Keong, Zarina Othman, \& Azhar Jaludin. (2011). Verbs and gender: the hidden agenda of a multicultural society. $3 \mathrm{~L}$; Language,Linguistics and Literature, The Southeast Asian Journal of English Language Studies, 17 (special issue). 61-73.

Nigles, L. M., \& Spencer, A.F. (2002). The Pictorial Representation of Gender and Physical Activity in Caldecott, Medal Winning Children's Literature: a Relational Analysis of Physical Culture. Education and Society, 7, 2.

Painter, C., \& Martin, J. (in press). Intermodal complementarity: Modelling affordances across image and verbiage in children's picture books. Ilha do Desterro: A Journal of English Language, Literatures in English and Cultural Studies.

Saedah Siraj. (1990). An analysis of Gender Stereotypes in Malay Language Elementary Reading Textbooks: Implications for Malaysian schools. PhD Thesis, University of Pittsburgh.

Taylor, F. (2003). Content Analysis and Gender Stereotypes in Children's Books. Teaching Sociology, 31(3), 300-311. http://dx.doi.org/10.2307/3211327

Turner-Bowker, D. M. (1996). Gender Stereotyped Descriptions in Children's Picture Books: Does "Curious Jane" Exist in the Literature? Sex Roles, 35, 461-488. http://dx.doi.org/10.1007/BF01544132

Van Leeuwen, T. J. (2008). Discourse and Practice: New Tools for Critical Discourse Analysis. Oxford University Press, New York, USA

Van Leeuwen. T. J., \& Jewitt, C. (2001). Handbook of visual analysis. London: Sage Publications.

Zarina Othman, Bahiyah Dato Hj Abdul Hamid, Mohamad Subakir Mohd Yasin, Yuen Chee Keong, \& Azhar Jaludin. (2012). Gender Images in Malaysian School Textbooks: A Frequency Analysis. The International Journal of Learning, 18(10), 101-126.

Zeegen, L. (2009). What is Illustration? Switzerland: RotoVision Publications. 